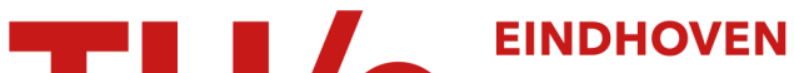 \\ UNIVERSITY OF \\ TECHNOLOGY
}

\section{Time-varying dependencies among mobility decisions and key life course events}

\section{Citation for published version (APA):}

Guo, J., Feng, T., \& Timmermans, H. J. P. (2019). Time-varying dependencies among mobility decisions and key life course events: an application of dynamic Bayesian decision networks. Transportation Research Part A: Policy and Practice, 130, 82-92. https://doi.org/10.1016/j.tra.2019.09.008

\section{Document license:}

TAVERNE

DOI:

10.1016/j.tra.2019.09.008

Document status and date:

Published: 01/12/2019

\section{Document Version:}

Publisher's PDF, also known as Version of Record (includes final page, issue and volume numbers)

\section{Please check the document version of this publication:}

- A submitted manuscript is the version of the article upon submission and before peer-review. There can be important differences between the submitted version and the official published version of record. People interested in the research are advised to contact the author for the final version of the publication, or visit the $\mathrm{DOI}$ to the publisher's website.

- The final author version and the galley proof are versions of the publication after peer review.

- The final published version features the final layout of the paper including the volume, issue and page numbers.

Link to publication

\section{General rights}

Copyright and moral rights for the publications made accessible in the public portal are retained by the authors and/or other copyright owners and it is a condition of accessing publications that users recognise and abide by the legal requirements associated with these rights.

- Users may download and print one copy of any publication from the public portal for the purpose of private study or research.

- You may not further distribute the material or use it for any profit-making activity or commercial gain

- You may freely distribute the URL identifying the publication in the public portal.

If the publication is distributed under the terms of Article $25 \mathrm{fa}$ of the Dutch Copyright Act, indicated by the "Taverne" license above, please follow below link for the End User Agreement:

www.tue.nl/taverne

Take down policy

If you believe that this document breaches copyright please contact us at:

openaccess@tue.nl

providing details and we will investigate your claim. 


\title{
Time-varying dependencies among mobility decisions and key life course events: An application of dynamic Bayesian decision networks
}

\author{
Jia Guo $^{\mathrm{a}}$, Tao Feng ${ }^{\mathrm{a}, *}$, Harry J.P. Timmermans ${ }^{\mathrm{a}, \mathrm{b}}$ \\ ${ }^{a}$ Urban Planning Group, Department of the Built Environment, Eindhoven University of Technology, PO Box 513, 5600 MB Eindhoven, the \\ Netherlands \\ ${ }^{\mathrm{b}}$ Department of Air Transportation Management, Nanjing University of Aeronautics and Astronautics, Jiangjun Avenue, Jiangning District, Nanjing \\ 211106, China
}

\section{A R T I C L E I N F O}

\section{Keywords:}

Life events

Concurrent

Lagged and lead effects

Dynamic Bayesian network

\begin{abstract}
A B S T R A C T
People's long-term mobility decisions depend on their current situation, past history and/or future plans. Consequently, models of long-term mobility decisions should take lagged, concurrent and/or lead effects into account. Contributing to the literature on long-term mobility analysis, this study develops an integrated framework for modeling the temporally interdependent choices related to residential change, job change and car purchasing decisions. Using retrospective life trajectory data collected through a Web-based survey, a dynamic Bayesian network model is estimated. Results show that different life domains are highly interdependent. Concurrent, as well as lagged and lead effects are observed.
\end{abstract}

\section{Introduction}

Recently, the view has emerged that people's long-term mobility decisions across different life-domains should be treated as a 'bundle' choice (e.g., Waddell et al., 2007; Paleti et al., 2011; Pinjari et al., 2011). While this might be too strong a position because rarely these choices are made truly simultaneously, we do acknowledge that residential change, job change, and car purchasing tend to be interdependent (e.g., Lerman, 1976; Rich and Nielsen, 2001). Moreover, changes in the demographic profile of individuals/ households, such as change in household composition, may trigger households to reconsider their current status for each of these domains. Consequently, incorporating life trajectory choices in travel demand forecasting is expected to provide a better understanding of the underlying decision processes. Rather than treating each life domain separately and independently, modeling codependent life trajectory choices captures the temporal relationships between these events. This approach enriches policy analyses in the sense it recognizes that improved travel options does not only impact activity-travel decisions, but may also affect other life domains. Classic models that focus on a single life domain by definition can never predict any behavioral response beyond the domain that is modeled and therefore are prone to biased policy recommendations.

Although the interest in examining interdependencies between residential, job and car ownership is not new, most prior empirical studies considered only two of these life domains in combination. Pinjari et al. (2011) formulated a simultaneous joint choice model of residential location, vehicle ownership, bicycle ownership, and commute mode choice, and found that these choice dimensions are interrelated. Similarly, Paleti et al. (2012) developed an econometric model system that simultaneously considered six activity-travel

\footnotetext{
* Corresponding author.

E-mail addresses: j.guo@tue.nl (J. Guo), t.feng@tue.nl (T. Feng), h.j.p.timmermans@tue.nl (H.J.P. Timmermans).
} 
choices in a unifying framework, showing existence of interdependencies among different choice dimensions. Most of these simultaneous choice models, which treat long-term and short-term decisions as an integrated choice, are based on cross-sectional data. In other words, temporal relationships among these and other life events (e.g. marriage, child birth, etc.) are not considered in the bundle choice.

In light of these considerations, a life course analysis that incorporates the temporal interdependencies between various life domains (Van der Waerden et al., 2003; Verhoeven et al., 2005, 2007a,b; Oakil et al., 2011; Beige and Axhausen, 2012; Scheiner and Holz-Rau, 2013; Zhang and Van Acker, 2017; Wang et al., 2018) has some clear advantages. The life course approach is based on the contention that life course events in a particular domain may lead people to reconsider their status in that and other life domains. Events may change household needs, or may create new opportunities in other domains. In that sense, the life course approach provides a rich framework for better understanding life domain choices and their effects.

To understand the interdependencies among various life domains and the timing of these decisions, two main modelling approaches have been applied. First, hazard and competing risk models have been developed. These models predict the interval times of life course events and their transitions as a function of the time elapsed since the last occurrence of the event and a set of covariates. For example, using a hazard model, Beige and Axhausen (2008) utilized the hazard model to compare different durations of residence, education, employment, and ownership of mobility tools. A major limitation is that these models cannot fully capture the complex direct and indirect relationship between the life course events and mobility decisions. Another modelling approach using Bayesian networks (e.g. Verhoeven et al., 2005; Wang, et al., 2018) allows dealing with complex interdependencies between different life domains. Their application requires the researcher to arbitrarily decide on a time interval. Given the network structure, the conditional probabilities of events are then predicted based on the chosen interval, and hence are sensitive to the chosen interval.

A limitation of these approaches is that the temporal dependency over multiple life events is treated either ignoring the indirect relationships or inferencing the conditional probabilities through a static network. To fill in this research gap, this study proposes and illustrates the use of a dynamic Bayesian network (DBN) which represents the same network structure in multiple time slices and modeling the temporal dependency between nodes at different time slices. Under the formalism of a DBN, first a causal network structure of life domain decisions within one time instance is developed. Then, the same structure of network is copied for each time instance belonging to a temporal range of interest. Finally, links connecting between the nodes in different time slices are established. Therefore, DBNs are more appropriate to model the temporal interdependencies between various life domains in real world.

The remainder of this paper is organized as follows: The next section briefly reviews the relevant literature. Section 3 presents the integrated framework, developed for modelling interdependencies between residential, job and car ownership over the life course. Following that, the Dynamic Bayesian network approach is presented. A brief description of the survey and data is outlined in Section 5. Next, the model estimation results are presented and discussed in Section 6. Conclusions and suggestions for future research are presented in the last section.

\section{Literature review}

A life course approach considers the timing and interdependencies in changes in various life domains. The domains considered depend on the field of study. In travel behavior analysis, in addition to demographic processes, long-term decisions that constitute the context of daily activity-travel decisions such as residential location, job and mobility tools possession choices are usually taken into account (e.g. Van der Waerden et al., 2003; Lanzendorf, 2003; Oakil et al., 2014; Zhang et al., 2014; Fatmi et al., 2017; Zhang, 2017, Wang et al., 2018).

Empirically, research based on the life course approach has unfolded along two lines. First, a substantial body of research has demonstrated that changes in household composition trigger residential/job relocation and/or mobility tools possession choice. For example, Rossi (1980), as one of the earliest studies, argued that changes in family size may render the current dwelling inadequate, thus creating dissatisfaction with the current dwelling. Habib et al. (2011) examined the effects of household structure change on job mobility decisions, and found that an increase in household size may increase household members' propensity to change job. Similarly, using the German Socioeconomic Panel data, Prillwitz et al. (2006) confirmed the key role of marriage and child birth on car ownership decisions. Similar findings were reported elsewhere in the literature (e.g., Verhoeven, et al., 2005; Lanzendorf, 2006; Beige and Axhausen, 2012).

Second, another stream of research has analyzed the impact of residential move and/or job relocation on mobility tools possession choice. For instance, Prillwitz et al. (2006) found that there is significant car ownership growth because of the residential change, suggesting that a change in residential location could be a main cause of transportation mode choice. Additional evidence about change in car ownership conditioned on residential relocation has been reported in other studies (e.g., Prillwitz et al., 2006; Choocharukul et al., 2007; Kim, 2008; Scheiner and Holz-Rau, 2013). In addition, several studies have investigated the impact of a change in job location on car ownership decisions. As an example, Lanzendorf (2006) concluded that a new job may stimulate individuals/households to purchase a car to save commuting time without changing their place of residence. Similar findings were reported in Prillwitz et al. (2006), Habib et al. (2011), Rashidi and Mohammadian (2011), and Yang et al. (2017) to name a few.

Most long-term mobility decisions are not instantaneous decisions. Earlier decisions may cause individuals to reconsider their current behavior, but in some cases with a time lag (Yamamoto, 2008; Fatmi and Habib, 2016). In other words, people may need time to adapt, which implies a lagged response to their changing needs. Alternatively, long-term decisions may also depend on individuals' plan, such as marriage and child birth (Oakil et al., 2014; Yu et al., 2017).

Empirically, to incorporate the time dimension into life course analysis, two different types of approaches have been applied. The first one is hazard and competing risks models have been applied. For instance, using a French data set, Yamamoto (2008) applied a 
competing risks model and found that most households acquired a vehicle one year after the birth of the first child, indicating that lagged effects of household structure change on the change of car ownership are larger than its immediate effect.

The second approach involves the use of Bayesian networks. A Bayesian network (BN) offers some advantages over econometric approaches in analyzing complex interdependencies among a set of variables. First, a BN has the ability to deal with uncertain and complex relationships hidden in the data. Especially in the context of life course mobility decisions in which state changes in one domain can be both cause and effect of changes in other domains, this is an important advantage. Second, a BN can incorporate different types of information, including empirical data, theoretical relationships, and expert knowledge. It is an ideal representation for combining prior knowledge and data (Heckerman, 1995). When testing a proposed theory using BN, one does not have to rely only on statistical evidence that may be biased, particularly for small samples.

Bayesian networks, however, have some disadvantages. The most important of these is that Bayesian networks were not designed to explicitly model temporal dependencies. Oakil et al. (2011) and Wang et al. (2018) used Bayesian network to model the lagged effects of employment change on moving house. However, these studies either treat the probability of a state of certain nodes at previous year as an independent node or transform two events at different time as one event (e.g. defined as increase or decrease), regardless of the contextual dependencies with other nodes which should be incorporated at the same (previous) time slice. In addition, treating the dynamic dependency in this static way may involve extra complexity in network structure learning.

Dynamic Bayesian network overcomes this disadvantage in that it assumes the same structural network at different time slices while the inference can be done between network nodes at inter- and intra- time slices. In other words, the conditional probability in dynamic Bayesian networks is time variant. In this paper, we apply a dynamic Bayesian network to examine the interrelations between change in household structure, residential change, job change, and car change.

\section{Conceptual considerations}

The aim of this study is to uncover the interdependencies of long-term mobility decisions under the influence of various life course events. Based on the literature and the available data, the life course events considered include change in household structure, residential change, job change and car change. Household structure change includes getting married and the birth of a child; residential mobility includes renting/purchasing the first apartment or house and moving house; changing job includes getting the first job and change of job; car change includes purchasing and/or replacing a car, regardless of buying the first/additional cars or going from one car to a different car. Furthermore, the influence of commuting time and socio-demographic characteristics on behavioral change is considered.

Decisions made during the current year are assumed to be influenced by past events, events in the same year and future events. Thus, the proposed framework examines concurrent, lagged and lead effects among various time-dependent events. The conceptual framework is presented in Fig. 1 where only the connections between different time instances are presented: the current $(t 0)$, previous $(t-1)$ and future $(t+1)$ situations. The round dot dashed lines present the one-year and two-year effects of future household structure change on current mobility decisions (lead/anticipation effects). Black bold lines represent the one-year effect of previous mobility decisions on current mobility decisions (lagged effects). Similarly, two-year lagged effects between household structure change and mobility decisions are shown by long dashed line.

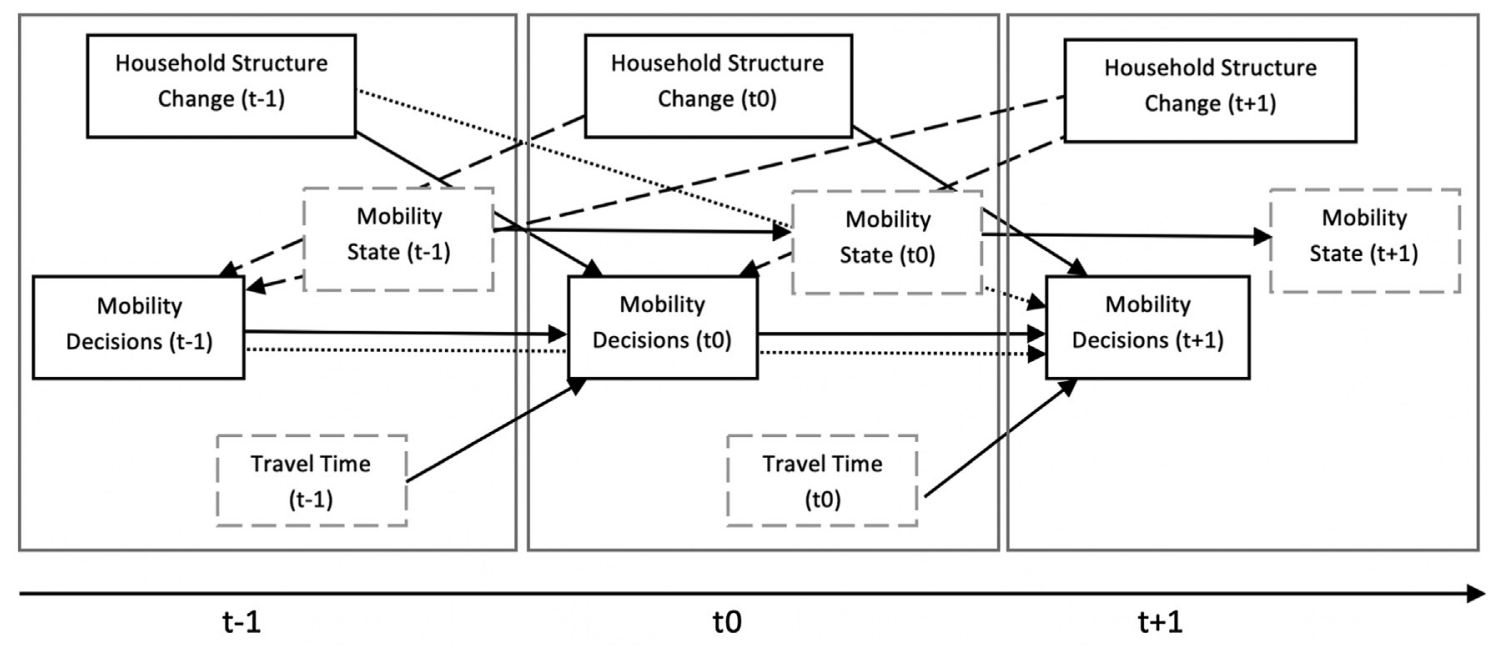

Fig. 1. Considered dependencies. 


\section{Modeling approach}

\subsection{Model specification}

Bayesian network models combine graph theory and probability theory. They consists of a directed acyclic graph (DAG) and an associated joint probability distribution of a large set of variables. The joint distribution of a set of variables equals:

$$
P\left(X_{1}, X_{2}, \cdots, X_{n}\right)=\prod_{i=1}^{n} P\left(X_{i} \mid \boldsymbol{P a}\left(X_{i}\right)\right)
$$

where $X_{1}, X_{2}, \cdots, X_{n}$ denotes a set of random variables (given nodes), $\boldsymbol{P a}\left(X_{i}\right)$ denotes the random variables corresponding to the parents of node $i$ in the DAG. $P\left(X_{i} \mid \boldsymbol{P a}\left(X_{i}\right)\right)$ denotes the conditional probability of node $X_{i}$ given its parents.

While the BN approach has been applied to model the interdependencies between life domains, conventional BN-based analysis is time-invariant. As an extension of BN, a dynamic Bayesian network is introduced in this study to capture temporal dependencies. In general, a DBN is defined as a pair of BNs $\left(B, B_{\rightarrow}\right)$, where $B$ is a BN model that defines the prior probability distribution $P\left(X_{t}\right)$, and $B_{\rightarrow}$ is a two-slice temporal Bayes net, which represents the instance of each variable at time $m+m^{\prime}$ and $m$. The probability of node $i$ over two time slices is defined as,

$$
P\left(X_{m+m}^{i}, \mid X_{m}^{i}\right)=\prod_{t=m}^{m+m^{\prime}} P\left(X_{t}^{i} \mid \boldsymbol{P a}\left(X_{t}^{i}\right)\right)
$$

where $X_{t}^{i}$ is the $i^{\prime}$ th node at time $t$, and $\boldsymbol{P a}\left(X_{t}^{i}\right)$ are the parent nodes of $X_{t}^{i}, t \in\left[m^{\prime}, m\right]$.

\subsection{Learning}

Similar to a BN, a useful property of DBNs is their ability to learn from observations. Application of a DBN involves two steps: determine the network structure (structure learning) and estimate the parameters that best describe the data given the network structure (parameter learning).

\subsubsection{Structure learning}

Structure learning aims at identifying the DAG, based on the association relationships between nodes. DBNs consider not only the dependencies between variables at one time instance but also the dependencies existing between several time slices. Several algorithms have been proposed to learn network structure (Murphy, 2003). Even though the MCMC (Markov Chain Monte Carlo) and Structural EM (Expectation Maximization) algorithms can be applied in dynamic Bayesian network structure learning, there applicability in the current study is limited due to too many nodes and number of time slices. Therefore, based on a priori knowledge, some constraints were enforced to reduce the degree of freedom in learning the structure of the network. That is, semi-structural learning is adopted in the current study where the structure within the same time slice is learned from the data, while the temporal dependency structure between different time instances is constructed based on our a priori knowledge.

Considering the complexity of the structural learning process in DBNs, especially in treating the constrained casual relationships between different time instances, we learn the network structure automatically by the data only for the base network. The temporal dependency is determined in accordance with the conceptual framework. More specifically, a Bayesian search algorithm is used for structure learning for one-time instances. For a more detailed explanation of the search algorithm, readers are referred to Cooper and Herskovits (1992) and Heckerman (1995). In addition, some constraints were set to simplify structure learning and deny some unreasonable "causal" relationships learned from the data. Setting these constraints will not affect the validity of the analysis.

1) Age, as a socio-demographic characteristic, is closely related to longer-term decisions. For example, older people are less likely to move house than younger people. Similarly, household structure change, residential and job change, as well as car change may all be influenced by the age of individuals. On the other hand, it is impossible that any life course event influences age. Thus, such effects are unidirectional between state/events and age.

2) Household structure change (getting married and child birth) may affect change of residence, job, and car change, while the opposite process is less likely to happen. Therefore, the effects of mobility decisions on household structure change are ignored in this study.

As discussed above, the network structure can be extracted from empirical data or simply by using domain knowledge. In this study, the dependencies between life course events across different time instances are determined based on the literature. First, household structure change is assumed to have both forward and backward effects on mobility decisions. Second, residential and job changes are assumed to have concurrent/lagged/lead effects on car change. Third, in terms of the residential/job location change, the current location choice is assumed to be one of the main factors that influences future location choice. Specifically, individuals' job location is assumed to have influence on their future home location choice. Assumption are also made between the current residential location and the future job location. Thus, it allows us to examine whether people prefer to live/work at the same location. Moreover, considering that residences and workers might relocate or purchase a car to avoid excess commuting time, travel time is assumed have effects on various mobility decisions. 
Table 1

Population density of the nine districts.

\begin{tabular}{|c|c|c|c|c|c|}
\hline District & Heping & Shenhe & Huanggu & Dadong & Tiexi \\
\hline Population & 651,557 & 711,914 & 818,015 & 681,607 & 908,652 \\
\hline Area $\left(\mathrm{km}^{2}\right)$ & 59 & 60 & 66 & 100 & 286 \\
\hline Population density (person/ $\mathrm{km}^{2}$ ) & 10,952 & 11,961 & 12,360 & 6807 & 3177 \\
\hline District & Hunnan & Yuhong & Shenbei & Sujiatun & \\
\hline Population & 333,563 & 445,834 & 320,337 & 427,158 & \\
\hline Area $\left(\mathrm{km}^{2}\right)$ & 734 & 499 & 884 & 782 & \\
\hline Population density (person/ $\mathrm{km}^{2}$ ) & 455 & 893 & 362 & 546 & \\
\hline
\end{tabular}

\subsubsection{Parameter learning}

With the given network structure, parameter learning aims at finding the optimal parameters for a given network structure and determining the conditional probability distribution of each observation variable. Parameter learning in DBN is similar to learning in BN, except that the estimation of parameters must be tied across time-slices. The expectation Maximization (EM) algorithm is capable of learning parameters from datasets that contain missing values. Thus, the EM algorithm was adopted in this study for parameter estimation in DBN.

\section{Survey and data collection}

\subsection{Survey}

In order to test the concurrent, lagged and lead effects between different mobility decisions and life course events, data from a retrospective survey in Shenyang, China, administered during the autumn of 2016, were used. As the capital city of Liaoning province, Shenyang is an important industrial city and a hub for transportation and commercial. The city is located in the northeast of China, covering five main districts in the central city (Heping, Shenhe, Huanggu, Dadong, Tiexi) and four districts in the surrounding areas (Hunnan, Yuhong, Shenbei, Sujiatun). The surrounded four districts are relatively newly developed areas. Population densities of the nine districts are shown in Table 1. Interviews were conducted in the nine districts based on a spatially stratified sample.

The retrospective survey asked respondents to recall their past life events. In particular, the data collection focused on four key life domains: household structure biography, residential history, job history, and car purchasing history. The household structure biography includes getting married and child birth. Residential history includes buying/changing to a new house. Job history includes the first job and job change. Moreover, the year when people moved house or changed jobs and the locations were asked. Car purchasing history includes questions related to buying a new car or changing the current car. Moreover, data about commuting time after each mobility decisions were collected. Considering the aim of this study, only people who have a job were considered.

Data were collected through face to face interviews. However, to reduce errors and time for the data cleaning process, interviewers used a questionnaire system that was originally developed by our research group for the design and implementation of webbased questionnaires. The system checks for correctness of data entries and warns for possible impossible or unlikely responses. Interviewers helped respondents to complete the questionnaire using an iPad. A potential problem of retrospective data is that richer life experiences may take substantial time. Thus, in order to reduce respondents' burden, we asked respondents to provide information up to a maximum of five of their last mobility decisions for each life domain. Respondents were given a small gift of appreciation. Interviewers were specially trained master students.

\subsection{Sample description}

Ultimately, the data from 414 out of the 450 respondents were used in the analyses. As shown in table 2 , an analysis of gender indicates that $48.3 \%$ of the sample are males and $51.7 \%$ are females. The average age in the sample is 36 years old. The distribution of marital status shows that $35.7 \%$ are singles, while only $8.2 \%$ are couples without children. $56 \%$ of the respondents have one or more child. Additionally, of the 414 surveyed respondents, in 2016, $64.0 \%$ of the respondents lived in the central city, $35.7 \%$ lived in the surrounding areas and only one individual did not live in these nine districts in Shenyang. Similarly, regarding the job location, $65.2 \%$ of the respondents work in the central city, 33.3\% work in the surrounding areas, and only $1.5 \%$ work in other cities.

The descriptive statistics of the mobility and life courses events data are presented in Table 3 . The frequencies of residential behavior change shows that $22.7 \%$ of the respondents never changed their residence, $43.5 \%$ changed their residence once, $23.2 \%$ moved house twice, and only about $10 \%$ of the respondents changed residence more than twice. Regarding job change, $40.1 \%$ of the respondents never changed jobs, 33.8\% changed their job once, 18.6\% changed their jobs twice, and only a few respondents (7.5\%) changed their jobs more than two times. As for car change, about $42 \%$ respondents mentioned they do not have a car in their household; about $39.4 \%$ have one car but never changed. Only approximately $18.6 \%$ respondents mentioned they have changed cars at least once. 
Table 2

Sample distribution.

\begin{tabular}{|c|c|c|c|}
\hline Variable & Classification & \# of Cases & Percentage (\%) \\
\hline \multirow[t]{2}{*}{ Gender } & Male & 200 & 48.3 \\
\hline & Female & 214 & 51.7 \\
\hline \multirow[t]{4}{*}{ Age } & $<25$ & 43 & 10.4 \\
\hline & $25-34$ & 170 & 41.1 \\
\hline & $35-50$ & 157 & 37.9 \\
\hline & $>50$ & 44 & 10.6 \\
\hline \multirow[t]{3}{*}{ Marital status } & Single & 148 & 35.7 \\
\hline & Couple without child & 34 & 8.2 \\
\hline & Couple with child & 232 & 56.0 \\
\hline \multirow[t]{3}{*}{ Living area } & Central city & 265 & 64.0 \\
\hline & Surrounding area & 148 & 35.7 \\
\hline & Other city & 1 & 0.2 \\
\hline \multirow[t]{3}{*}{ Working area } & Central city & 270 & 65.2 \\
\hline & Surrounding area & 138 & 33.3 \\
\hline & Other city & 6 & 1.5 \\
\hline
\end{tabular}

Table 3

Descriptive statistics of mobility decisions.

\begin{tabular}{|c|c|c|c|}
\hline Mobility decisions & & \# of Cases & Percentage (\%) \\
\hline \multirow[t]{5}{*}{ Residential change } & Never moved house & 94 & 22.7 \\
\hline & Moved house once & 180 & 43.5 \\
\hline & Moved house twice & 97 & 23.2 \\
\hline & Moved house three times & 31 & 7.5 \\
\hline & Moved house more than three times & 13 & 3.1 \\
\hline \multirow[t]{5}{*}{ Job change } & Never changed jobs & 166 & 40.1 \\
\hline & Changed job once & 140 & 33.8 \\
\hline & Changed job two times & 77 & 18.6 \\
\hline & Changed job three times & 21 & 5.1 \\
\hline & Changed job more than three times & 10 & 2.4 \\
\hline \multirow[t]{5}{*}{ Car change } & Never had cars & 174 & 42.0 \\
\hline & Always the same vehicle & 163 & 39.4 \\
\hline & Changed cars once & 60 & 14.5 \\
\hline & Changed cars twice & 16 & 3.9 \\
\hline & Changed cars more than twice & 1 & 0.2 \\
\hline
\end{tabular}

\section{Analysis and results}

\subsection{Results of structure learning}

The Bayesian search algorithm was used in the structure learning process within one time slice. The prior link probability was set as the default value 0.001 for the structure learning process. The learned causal dependencies between the variables within one timeslice are shown in Fig. 2(a). Household mobility decisions include two life course events within households: getting marriage (marry) and child birth (birth); life course mobility decisions include three life domains: residential change (changeH), work change (changeW), and car change (changeC). Residential location and workplace are represented as locationH and locationW, respectively. As expected, household structure change is closely associated with other life course mobility decisions. The results clearly present a direct concurrent relationship between car change and residential and work change, which is in line with previous studies. Moreover, life course mobility decisions are also shown to have concurrent effects on state variables, i.e. travel time (tt). Lastly, the sociodemographic variable 'age' is directly linked with various life course mobility decisions.

The causal relationship with temporal dependencies are represented in Fig. 2(b). Orange numbers in rectangles represent one and two years lagged effects between various mobility decisions, while green numbers represent previous location choice influences people's future location choice. In the unrolling structure of the DBN model, the same network is copied to each time instance. Here, the lead effects between life course events and various mobility decisions are added manually in the unrolling structure network. In total, five time slices are constructed based on five years data.

\subsection{Results of parameter learning}

Based on the network structure presented above, the EM algorithm was used to estimate the conditional probability tables for 


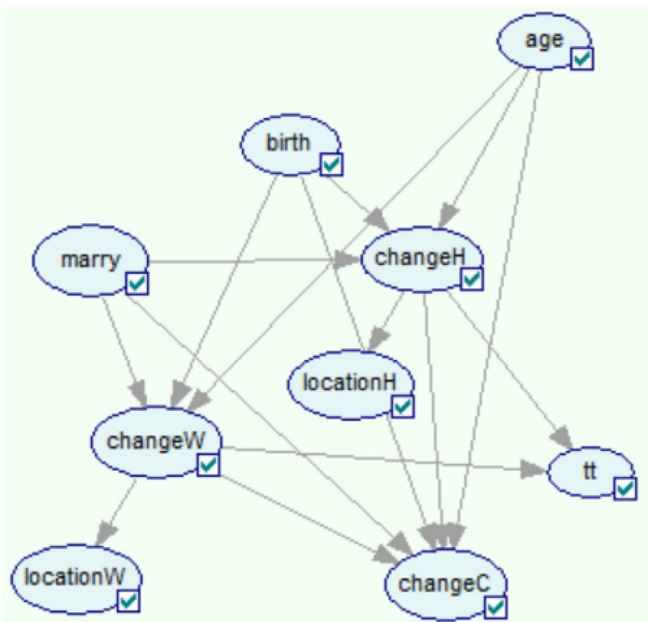

(a) Learned network structure of concurrent effects

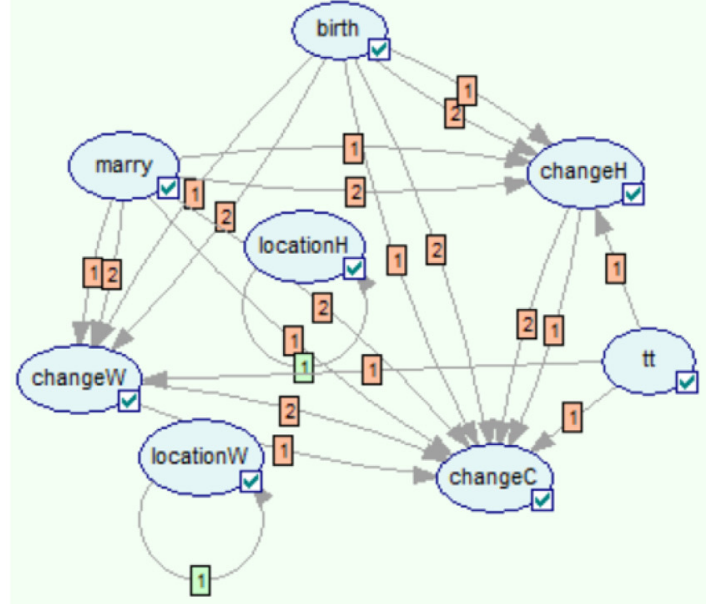

(b) Network structure of lagged effects

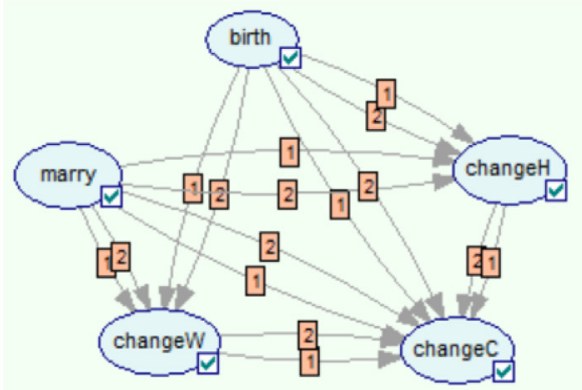

c. Structure of lead effects

Fig. 2. The network structure.

each time node based on the retrospective data. Fig. 3 represents the overall probability distribution for each node and the interdependency between nodes and different time slices. Bayesian networks can portray the direct and indirect dynamic effects between the nodes of interest based on provided evidence and compare the change in the probabilities with and without an event. The evidence means that the probability of a state of a certain node is known or instantiated. When providing evidence for certain nodes, the probability of the states of others nodes may be updated depending on their structural connection. To analyze the positive or negative causal effects between different mobility decisions and states given evidence on other nodes, in this study, both the updated probability and the relative probability differences are calculated. The relative probability differences are defined as the difference between the updated and prior probability divided by the prior value. Assume the prior probability of a certain state of a variable $\times$ is $p_{0}$, the updated probability is $p^{\prime}$, the relative probability difference $p_{\text {diff }}$ is calculated as follows,

$$
p_{\text {diff }}=\frac{p_{0}-p}{p_{0}}
$$

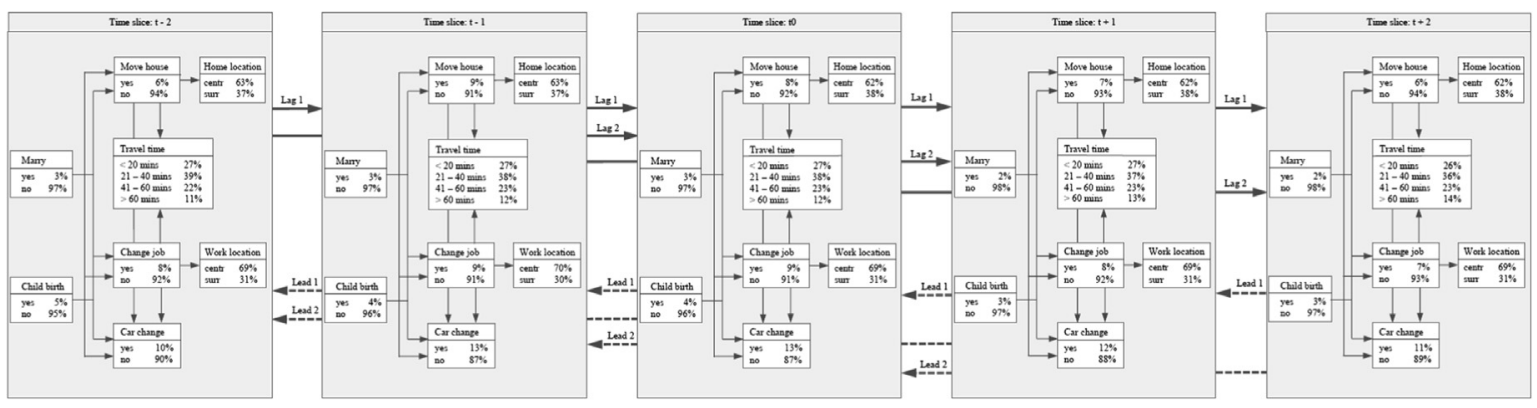

Fig. 3. Estimated probability distribution. 
Table 4

Conditional probability and relative probability differences (in parentheses) of various mobility decisions for different age categories.

\begin{tabular}{|c|c|c|c|}
\hline Age & Residential change & Job change & Car change \\
\hline No change & $8 \%$ & $9 \%$ & $13 \%$ \\
\hline$<25$ & $19 \%(141.7 \%)$ & $38 \%(322.2 \%)$ & $33 \%(153.3 \%)$ \\
\hline $25-34$ & $7 \%(-9.1 \%)$ & $11 \%(22.2 \%)$ & $12 \%(-6.7 \%)$ \\
\hline $35-50$ & $7 \%(-9.1 \%)$ & $7 \%(-22.2 \%)$ & $12 \%(-6.7 \%)$ \\
\hline$>50$ & $10 \%(25.0 \%)$ & $11 \%(22.2 \%)$ & $19 \%(46.7 \%)$ \\
\hline
\end{tabular}

The relative probability difference can be negative or positive, which means the probability of the predicted event decreases or increases given the evidence of certain variables/events, respectively. A value close to 0 means that the predicted event is not influenced by the given variables/events.

The conditional probabilities in DBN can reflect the effects of state variables between time slices. The relevant conditional probability tables, which describe the temporal interdependencies between different life domains are shown in the following sections.

\subsubsection{Mobility decisions for different age categories}

Taking age as the parent node, both the updated probability and the relative probability differences of various mobility decisions (shown in parentheses) are presented in Table 4. It is found that age has a direct impact on residential and job mobility decisions and on car change. The socio-demographic variable, 'age' was categorized into four categories: under 25, 25-34, 35-50, and over 50. For the age category under 25 , the conditional probability for all mobility decisions increases, indicating that young people are more likely to change their current residence, job and car. The biggest increase in the conditional probabilities among these mobility decisions is for the work domain (13\%), which suggests that the probability of changing jobs is bigger for younger generations. In contrast, people aged 25-34 and 35-50 are more likely to have a stable life and are less likely to change their current status. People aged over 50 have higher probability of changing residence, work and car than the middle age categories. The reason may be that they have more money and time, thus having the capability and willingness to change. This result is consistent with the findings of earlier studies, including Habib et al. (2011) who also found that younger people are more likely to change jobs than older people.

\subsubsection{Mobility decisions given different levels of household structure change}

Given evidence of a change in household structure, Table 5 reports the updated conditional probability and relative probability differences related of various mobility decisions. Here, ' $t$ ' indicates the year where a certain event occurred; ' $t-1, t-2$ ' indicate one-year and two-year ahead of the event, and ' $t+1, t+2$ ' indicate one-year and two-year later than the event. It shows that various life course mobility decisions are strongly influenced by a change in household structure. This finding emphasizes the importance of a change in household structure as a trigger for residential relocation and car change.

The conditional probabilities show that both marriage and child birth have a positive effect on the probability of moving house, which is consistent with earlier findings in the literature. However, effects differ in size for different time instances. In general, child birth has a larger effect on residential mobility than getting married. Obviously, the birth of a child implies new responsibilities. As a consequence, household may be more likely to find a larger house in response to the increase in household size. The biggest increase in the the conditional probability occurs for getting married at time $t$ (from $8 \%$ to $41 \%$ ), which indicates that the concurrent effect of getting married is larger than both the lagged and lead effects. However, a reverse effect was found between child birth and residential change, with lagged and lead effects both being larger than the concurrent effect. This means that people are more likely to move house in the year of marriage, but less likely to move when a child is born. This is understandable considering that making the necessary arrangements for having a child and moving house in the same year may not be easy. Additionally, the comparison of the changes in probabilities across different time slices shows that one-year temporal effects are in general larger than two-year temporal

Table 5

Conditional probability and relative probability differences (in parentheses) of residential, job and car change given the change in household structure.

\begin{tabular}{|c|c|c|c|c|}
\hline Household structure change & & Residential change $(t)$ & Job change $(t)$ & Car change $(t)$ \\
\hline No change & & $8 \%$ & $9 \%$ & $13 \%$ \\
\hline \multirow[t]{5}{*}{ Getting married } & $t-2$ & $17 \%(112.5 \%)$ & $14 \%(55.6 \%)$ & $37 \%(184.6 \%)$ \\
\hline & $t-1$ & $18 \%(125.0 \%)$ & $24 \%(166.7 \%)$ & $36 \%(176.9 \%)$ \\
\hline & $t$ & $41 \%(412.5 \%)$ & $21 \%(133.3 \%)$ & $37 \%(184.6 \%)$ \\
\hline & $t+1$ & $19 \%(125.0 \%)$ & $23 \%(155.6 \%)$ & $30 \%(130.8 \%)$ \\
\hline & $t+2$ & $17 \%(112.5 \%)$ & $21 \%(133.3 \%)$ & $31 \%(138.5 \%)$ \\
\hline \multirow[t]{5}{*}{ Child birth } & $t-2$ & $20 \%(150.0 \%)$ & $18 \%(100.0 \%)$ & $29 \%(123.1 \%)$ \\
\hline & $t-1$ & $23 \%(187.5 \%)$ & $17 \%(88.9 \%)$ & $28 \%(115.4 \%)$ \\
\hline & $t$ & $16 \%(100.0 \%)$ & $15 \%(66.7 \%)$ & $31 \%(138.5 \%)$ \\
\hline & $t+1$ & $24 \%(200.0 \%)$ & $17 \%(88.9 \%)$ & $32 \%(146.2 \%)$ \\
\hline & $t+2$ & $18 \%(125.0 \%)$ & $17 \%(88.9 \%)$ & $30 \%(130.8 \%)$ \\
\hline
\end{tabular}


Table 6

Conditional probability and relative probability differences (in parentheses) of change in car change given residential and job change.

\begin{tabular}{lll}
\hline Mobility decisions & & Car change $(t)$ \\
\hline No change & & $13 \%$ \\
Residential change & $t-2$ & $29 \%(123.1 \%)$ \\
& $t-1$ & $29 \%(123.1 \%)$ \\
& $t$ & $31 \%(138.5 \%)$ \\
Job change & $t+1$ & $19 \%(46.2 \%)$ \\
& $t+2$ & $17 \%(30.8 \%)$ \\
& $t-2$ & $27 \%(107.7 \%)$ \\
& $t-1$ & $30 \%(130.8 \%)$ \\
& $t+1$ & $28 \%(115.4 \%)$ \\
& $t+2$ & $19 \%(46.2 \%)$ \\
\end{tabular}

effects for both lagged and lead effects.

In terms of job change, the concurrent, lead, and one-year lagged effects of child birth are found to be smaller than the effects of getting married. In addition, the comparison of conditional probability between different time instances in the case of child birth shows that the lagged and lead effects (17\%) are slightly larger than the concurrent effect (15\%).

Looking at the interdependencies between change in household structure and change in car ownership, results show that getting married and child birth have different effects on car change. Relative to the situation without children, baby birth may create new travel needs to transport the child to a day care center and other locations, as well as the need to combine work and household tasks, which may increase the probability of car use. This result is in line with other empirical findings (e.g. Verhoeven et al., 2005; Beige and Axhausen, 2012). Taking a closer look at the temporal effects, the concurrent and lagged effects of getting married are found larger than the lead effects. Such results are not found in case of child birth.

\subsubsection{Car change given residential and job changes}

Temporal interdependencies between residential/job change and car change are shown in Table 6 . It represents the conditional probability of change in car ownership given evidence of residential and job change at different time slices. Results show that residential and job change increase the probability of car change. The concurrent, one-year and two-year lagged effects are found to be nearly two times higher, while the lead effects are much smaller than the corresponding concurrent and lagged effects. This means that the anticipated occurrence of future changes in residence and work has a bigger influence on the decision of changing car in the current year, compared with the past change in residence/work.

In addition, the magnitude of the change in probability differs for different time instances. Comparing the results documented in Tables 5 and 6, the one-year and two-year lead effects of residential and job change on car change are smaller than the corresponding effects for the getting married and child birth. In other words, individuals/households are likely to buy/change a car in anticipation of getting married or baby birth relative to the change of residence and job. The probability of car change is, however, relatively small.

\subsubsection{Residential and job location change}

Apart from the effects of change in household structure, commuting time and social demographics, location is considered important for different mobility decisions. The decision where to live and where to work may partly depend on individuals' past residential and job choice decisions. To investigate this assumption, we examined the conditional probabilities of residential and job location change at time $t$, given evidence of moving house or changing job at time $t-1$, separately (Table 7). Residential and job location at time $t-1$ are shown in the left two columns, and the percentages of people living or working in the central city at time $t$ are shown in the right two columns.

\section{Table 7}

Conditional probability and relative probability differences (in parentheses) of change in residential/job location at time $t$ given change of location at time $t-1$ and mobility decisions.

\begin{tabular}{lll}
\hline Mobility decisions & & $\begin{array}{l}\text { Job location }(t) \\
\text { Job change } \\
\text { Residential change }\end{array}$ \\
\hline No change & Work location $(t-1)$ & $62 \%$ \\
Residential location $(t-1)$ & Central city & $($ Central city) \\
Central city & Surrounding area of the city & $73 \%(17.7 \%)$ \\
Central city & Central city & $68 \%(9.7 \%)$ \\
Surrounding area of the city & Surrounding area of the city & $60 \%(-3.2 \%)$ \\
Surrounding area of the city & & $75 \%(27.5 \%)$ \\
\hline
\end{tabular}


Table 8

Conditional probability and relative probability differences of commuting time at time $t$ given commuting time at time $t-1$ and various mobility decisions.

\begin{tabular}{|c|c|c|c|c|}
\hline Mobility decisions & & Residential change $(t)$ & Work change $(t)$ & Car change $(t)$ \\
\hline \multirow[t]{5}{*}{ Commuting time $(t-1)$} & No change & $8 \%$ & $9 \%$ & $13 \%$ \\
\hline & $<20 \min$ & $8 \%(0.0 \%)$ & $8 \%(-11.1 \%)$ & $12 \%(-6.7 \%)$ \\
\hline & $20-40 \mathrm{~min}$ & $7 \%(-16.7 \%)$ & $10 \%(11.1 \%)$ & $12 \%(-6.7 \%)$ \\
\hline & $41-60 \mathrm{~min}$ & $9 \%(8.3 \%)$ & $10 \%(11.1 \%)$ & $14 \%(6.7 \%)$ \\
\hline & $>60 \mathrm{~min}$ & $9 \%(16.7 \%)$ & $10 \%(11.1 \%)$ & $14 \%(6.7 \%)$ \\
\hline
\end{tabular}

It is found that the current residential and work location have a clear impact on individuals' future location choice. For example, for people who live and work in the central city at time $t-1$, if a moving house event is observed at time $t$, the probability of moving to the central is $73 \%$ (increased by $17.7 \%$ ). Similarly, given evidence of changing job at time $t$, the probability of their job being located in the central city at time $t$ is $88 \%$ (increased by 27.5\%). Similar results are found for the people who both work and live in the surrounding areas of the city. Only about $21 \%$ and $22 \%$ of the people choose to move house or change job to the central city, respectively. These results confirm our assumption discussed in Section 5.2 that people tend to live close to their job location.

Results also show that people who live and work in different areas have a stronger intention to relocate close. They are more likely to adjust their work location to meet their residential location in the relocation process. For example, as shown in Table 7, for people who live in the central city and work in the surrounding area of the city at time $t-1$, when changing home is observed at time $t$, the probability of their new residence location being in the central city only increases by $9.7 \%$. Likewise, when changing job at time $t$ is observed, the probability of their new workplace in the central city only increases by $8.7 \%$. Comparing with people who live and work in the central city $(17.7 \%$ and $27.5 \%)$, the increase of probability is relatively small $(9.7 \%$ for residential location change and $8.7 \%$ for work location change). Similarly, for people who live in the surrounding area of the city and work in the central city at time $t-1$, when residential/job change at time $t$ is observed, the probabilities of their next residence/job location in the central city decreases by $3.2 \%$ and $31.9 \%$, respectively.

\subsubsection{Commuting time change}

Considering the important role of commuting time in different mobility decisions, Table 8 presents the probability change of various mobility decisions at time $t$ given the evidence of commuting time at time $t-1$. Commuting time is categorized into four levels: less than $20 \mathrm{~min}, 20-40 \mathrm{~min}, 41-60 \mathrm{~min}$, and longer than one hour. Results show that commuting time is a contributor for people to change residences, work and car change. In general, the longer the commuting time, the higher the probability people move house, change job or cars. More specifically, the probability of moving house or changing cars increases when commuting time is longer than $40 \mathrm{~min}$. For changing jobs, the probability increases when commuting time exceeds 40 min. It indicates that longer commuting time increases the probability of changing jobs. This conclusion is in line with the previous findings by Habib et al. (2011). However, it should be noted that, compared with the results of various life course mobility decisions, the effects of commuting time are relatively small. This probably indicates that long-term decisions are more dependent on anticipated life course events rather than on travel related attributes like commuting time.

\section{Conclusions and discussions}

People hold a series of aspirations related to different life domains. In an attempt to better understand the decisions making process, this study proposes an integrated framework to comprehensively explore the interdependencies between various life domains. In addition, people have different needs at different life stages, interdependencies between life events and mobility decisions may change over time. To incorporate the time dimension into the life course analysis, based on a retrospective data, a dynamic Bayesian network was estimated to capture the temporal interdependencies between different mobility decisions.

The model results evidence the existence of concurrent and temporal interdependencies between different mobility decisions. Both getting married and child birth are found to likely increase the probability of residence/job change and car change. Likewise, both residence and job relocation are found have positive effects on car change, indicating that either moving house or changing job may increase people' needs of purchasing/changing a car.

In terms of the relevance of long-term policy indications, people's mobility decisions over the life course cannot be ignored. According to our results, the proposed framework coincides with the life-oriented approach where the timing in mobility decisions play an important role. Individuals/households make their decisions based on their past experiences and future expectations. In terms of the dynamic interdependencies, concurrent and lagged effects are found larger than the lead effects, indicating that in general the probability of people take an action to change before a triggering event is smaller than after these events happen. Results also show that temporal one-year effects are larger than two-year effects for both lagged and lead effects. Thus, this study sheds light on better understanding the mechanisms underlying long-term mobility decisions in response to various life course events.

Despite the dynamic interdependencies between mobility decisions in different life domains being investigated, our results are based on the observations that each individual is the decision maker, ignoring the role of other household members. However, household members in general share various resources, the decision on long-term mobility are often jointly made by multiple members. Thus, further research is needed in future to modeling the decision making at the household level, e.g. what role a wife and 
a husband in a dual-earner household plays in the decision-making process. Additionally, this study is based on a retrospective data which was collected in the context of Chinese city, the dynamics influenced by the contextual differences in developing countries and developed countries would be also an interesting extension to study the behavioral adaption. We leave these potential points open for future studies.

\section{Acknowledgement}

This research was supported by the China Scholarship Council (CSC). We would like to thank the China Scholarship Council for providing the funding for this PhD study.

\section{Appendix A. Supplementary material}

Supplementary data to this article can be found online at https://doi.org/10.1016/j.tra.2019.09.008.

\section{References}

Beige, S., Axhausen, K.W., 2008. Long-term and mid-term mobility decisions during the life course: experiences with a retrospective survey. IATSS Res. 32 (2), 16-33. Beige, S., Axhausen, K.W., 2012. Interdependencies between turning points in life and long-term mobility decisions. Transportation 39 (4), $857-872$.

Choocharukul, K., Tan Van, H., Fujii, S., 2007. Psychological effects of travel behavior on preference of residential location choice. Transp. Res. Part A 42 (1), 116-124. Cooper, G.F., Herskovits, E., 1992. A Bayesian method for the induction of probabilistic networks from data. Machine Learn. 9 (4), $309-347$.

Fatmi, M.R., Chowdhury, S., Habib, M.A., 2017. Life history-oriented residential location choice model: a stress-based two-tier panel modeling approach. Transp. Res. Part A 104, 293-307.

Fatmi, M.R., Habib, M.A., 2016. Longitudinal vehicle transaction model: assessing the lead and lagged effects of longer-term changes and life-cycle events. Transport. Res. Record: J. Transport. Res. Board 2566, 11-21.

Habib, M.A., Miller, E.J., Mans, B.T., 2011. Modeling of job mobility and location choice decisions. Transport. Res. Record: J. Transport. Res. Board 2255, 69-78. Heckerman, D., 1995. A Tutorial on Learning with Bayesian Networks. Technical Report MSR-TR-95-06. Microsoft Research.

Kim, C.S., 2008. Commuting time stability: a test of a co-location hypothesis. Transp. Res. Part A 42 (3), 524-544.

Lanzendorf, M., 2003. Mobility biographies. A new perspective for understanding travel behaviour. 10th International Conference on Travel Behaviour Research, Lucerne.

Lanzendorf, M., 2006. Key events and their effect on mobility biographies: the case of child birth. Paper presented at the 11th Conference of the International Association of Travel Behavior Research, Kyoto, Japan.

Lerman, S.R., 1976. Location, housing, automobile ownership and mode to work: a joint choice model. Transport. Res. Record: J. Transport. Res. Board 610, 6-11. Murphy, K.P. 2003. Dynamic Bayesian networks: Representation, Inference and Learning. Ph.D. Thesis, UC Berkeley, USA.

Oakil, A.T.M., Ettema, D.F., Arentze, T.A., Timmermans, H.J.P., 2011. Longitudinal model of longer term mobility decisions: framework and first empirical test. J. Urban Devel. 137 (3), 220-229.

Oakil, A.T.M., Ettema, D.F., Arentze, T.A., Timmermans, H.J.P., 2014. Changing household car ownership level and life cycle events: an action in anticipation or an action on occurrence. Transportation 41 (4), 889-904.

Paleti, R., Bhat, C., Pendyala, R., 2012. An integrated model of residential location, work location, vehicle ownership, and commute tour characteristics. Transport. Res. Record: J. Transport. Res. Board 2382, 162-172.

Paleti, R., Copperman, R.B., Bhat, C.R., 2011. An empirical analysis of children's after school out-of-home activity-location engagement patterns and time allocation. Transportation 38 (2), 273-304.

Pinjari, A.R., Pendyala, R.M., Bhat, C.R., Waddell, P.A., 2011. Modeling the choice continuum: an integrated model of residential location, auto ownership, bicycle ownership, and commute tour mode choice decision. Transportation 38 (6), 933-958.

Prillwitz, J., Harms, S., Lanzendorf, M., 2006. Impact of life-course events on car ownership. Transport. Res. Record: J. Transport. Res. Board 1986, 91-177.

Rashidi, T.H., Mohammadian, A.K., 2011. A dynamic hazard-based system of equations of vehicle ownership with endogenous long-term decision factors incorporating group decision making. J. Transp. Geogr. 19 (6), 1072-1080.

Rich, L., Nielsen, O., 2001. A microeconomic model for car ownership, residence and work location. European Transport Conference, PTRC, Cambridge, UK.

Rossi, P.H., 1980. Why Families Move. Sage Publications, Beverley Hills, CA.

Scheiner, J., Holz-Rau, C., 2013. Changes in travel mode choice after residential relocation: a contribution to mobility biographies. Transportation 40 (2), 431-458.

Van der Waerden, P.J.H.J., Borgers, A.W.J., Timmermans, H.J.P., 2003. Key events and critical incidents influencing transport mode choice switching behavior: an exploratory study. Paper presented at the Transportation Research Board 82nd Annual Meeting, Washington, DC.

Verhoeven, M., Arentze, T.A., Timmermans, H.J.P., Van der Waerden, P.J.H.J., 2005. Modelling the impact of key events on long-term transport mode choice decisions: decision network approach using event history data. Transport. Res. Record: J. Transport. Res. Board 1926, $106-114$.

Verhoeven, M., Arentze, T.A., Timmermans, H.J.P., Van der Waerden, P.J.H.J., 2007a. Simulating the influence of life trajectory events on transport mode behavior in an agent-based system. In: IEEE Intelligent Transportation Systems Conference, pp. 107-112.

Verhoeven, M., Arentze, T.A., Timmermans, H.J.P., Van der Waerden, P.J.H.J., 2007b. Examining temporal effects of lifecycle events on transport mode choice decisions. Int. J. Urban Sci. 11 (1), 1-13.

Wang, B., Rasouli, S., Timmermans, H.J.P., Shao, C., 2018. Relationships between consecutive long-term and mid-term mobility decisions over the life course: a Bayesian network approach. Transport. Res. Record: J. Transport. Res. Board. 2672 (47), 159-170.

Waddell, P., Bhat, C.R., Eluru, N., Wang, L., Pendyala, R.M., 2007. Modeling the interdependence in household residence and workplace choices. Transport. Res. Record: J. Transport. Res. Board 2003, 84-92.

Yamamoto, T., 2008. The Impact of life-course events in vehicle ownership dynamics: the cases of France and Japan. IATSS Res. 32 (2), $34-43$.

Yang, M., Wu, J., Rasouli, S., Cirillo, C., Li, D., 2017. Exploring the impact of residential relocation on modal shift in commute trips: evidence from a quasi-longitudinal analysis. Transp. Policy 59, 142-152.

Yu, B., Zhang, J., Li, X., 2017. Dynamic life course analysis on residential location choice. Transport. Res. Part A 104, $281-292$.

Zhang, J., 2017. Life-Oriented Behavioral Research for Urban Policy. Springer, Japan.

Zhang, J., Van Acker, V., 2017. Life-oriented travel behavior research: an overview. Transp. Res. Part A 104, 167-178.

Zhang, J., Yu, B., Chikaraishi, M., 2014. Interdependences between household residential and car ownership behavior: a life history analysis. Transport Geogr. 34, $165-174$. 